\title{
Commentary: Discovery of the Sun's million-degree hot corona
}

\author{
Alexander J. B. Russell * \\ School of Science \& Engineering, University of Dundee, Scotland, United Kingdom \\ Keywords: solar corona, million-degree hot corona, Alfvén, discovery of hot corona, x-ray corona, Edlén, Grotrian, \\ Coronal heating
}

\section{A commentary on}

Discovery of the Sun's million-degree hot corona

by Peter, H., and Dwivedi, B. N. (2014). Front. Astron. Space Sci. 1:2. doi: 10.3389/fspas.2014.00002

\section{OPEN ACCESS}

Edited by:

Valery M. Nakariakov,

University of Warwick,

United Kingdom

Reviewed by:

Eric Ronald Priest,

University of St Andrews,

United Kingdom

*Correspondence:

Alexander J. B. Russell

a.u.russell@dundee.ac.uk

Specialty section:

This article was submitted to

Stellar and Solar Physics,

a section of the journal

Frontiers in Astronomy and Space

Sciences

Received: 25 January 2018

Accepted: 06 March 2018

Published: 21 March 2018

Citation:

Russell AJB (2018) Commentary: Discovery of the Sun's million-degree

hot corona.

Front. Astron. Space Sci. 5:9

doi: 10.3389/fspas.2018.00009
Peter and Dwivedi (2014) have performed an excellent service by highlighting the important paper of Alfvén (1941). However, a critical review finds flaws in their thesis that "the credit for discovering that the corona is hot should go to Hannes Alfvén," which, in my view, exaggerates his role relative to the Swedish spectroscopist Bengt Edlén and the German astrophysicist Walter Grotrian.

The main criticism is that Peter and Dwivedi (2014) misdated the solution to the coronal lines problem by at least two years. Edlén (1943) is frequently cited (it is a detailed account in a prestigious and accessible journal), however, the discovery paper was Edlén (1941). Furthermore, Edlén circulated preliminary findings internationally by June 1939 (Swings, 1943) and Alfvén likely knew of his compatriot's work at that stage. For context, Alfvén and Edlén were closely connected: both studied at Uppsala University from 1926 and 1927, both completed PhDs in 1934 advised by Manne Siegbahn, and both taught at Uppsala until Alfvén and Siegbahn moved to nearby Stockholm. Certainly Alfvén (1941) referred prominently to Edlén's results as prior motivation for considering the possibility of a hot corona. I therefore suggest that Alfvén (1941) is better regarded as a swift response to Edlén's breakthrough instead of a forerunner.

Next, let us examine Peter and Dwivedi's (2014) claims that Edlén "estimated the temperature to be about 250,000 K," "did not use the high degree of ionization" and "was not fully aware of the implications." From Edlén (1941): "This indicates a maximum abundance for ions with ionization potentials with about 400 volts. In this connection we may remind that Lyot, assuming the profiles observed for some coronal lines as due to a thermal Doppler effect in oxygen atoms, found an equivalent temperature of $660000^{\circ}$ which becomes $2300000^{\circ}$ when recalculated to iron atoms." Edlén uses the equivalence between temperature units of $\mathrm{eV}$ and kelvin, which was well understood at the time (e.g., Alfvén, 1941; Hunter, 1942), and he refers explicitly to a MK corona, which refutes entirely any assertion that he "did not dare to draw that conclusion."

It is also important to weigh the arguments and evidences. The electron velocity deduced from $\mathrm{H}$ and $\mathrm{K}$ lines (Grotrian, 1931, 1934) relies on assumptions about the light source and scattering particles. Temperatures based on broadening of emission lines (Lyot, 1937) could instead signify turbulence. Highly-ionized iron and the corona both having lines at $6374 \AA$ and $7892 \AA$ (Grotrian, 1939, using data from Edlén 1937a,b) could be coincidence, as had happened before. Alfvén’s own argument, namely that, if the corona is in hydrostatic equilibrium, then its broad extent would 
imply MK temperatures, is not by itself conclusive, since it is possible that the corona is not in hydrostatic equilibrium. Alfvén (1941) acknowledged this limitation and addressed it by collecting six other pieces of evidence for high-energy particles in the Sun, of which Edlén's and Grotrian's are the only ones indicating a general $\mathrm{MK}$ temperature, then arguing that his interpretation was consistent with these.

It was Edlén's comprehensive identification of fifteen lines responsible for more than $97 \%$ of the coronal emission intensity (Edlén, 1941) that clinched the argument and convinced scientists of the reality of a hot corona. Despite World War II, his paper circulated internationally and Scientific American and Telescope ran articles within months (Hufbauer, 1991). Reaction papers followed in Nature (Hunter, 1942) and ApJ (Swings, 1943). At thirty-eight, Edlén was made Professor of Physics at Lund University and received the Royal Astronomical Society Gold Medal "for his identification of the origin of the principal lines in the coronal spectrum" (Milne, 1945). He remains the medal's youngest recipient since Hale in 1904.

An important piece of evidence for the significance of Edlen's work comes from Alfven's own writings. In the first paper on coronal heating by MHD waves (Alfvén, 1947) and in "Cosmical Electrodynamics" (Alfven, 1950) one finds, "since B. Edlén's identification of the corona lines it can be considered as certain that the temperature of the corona is of the order of $10^{6}$ degrees."

Few discoveries are due to one person. A decade of research by Grotrian $(1931,1934)$ prepared the way, and his realization that Edlén's data matched two coronal lines (Grotrian, 1939) caused him to write to Edlén in 1937 that "perhaps it would be worthwhile to look into the question" (Edlén, 1945).

There should be a place for Alfvén too. Edlén's main aim was to identify the source of the coronal lines, and while he saw the implications, it would have been against his high standards of certainty (Persson and Martinson, 1994) to insist on all particles having high energy or on thermal equilibrium. Alfvén's different expertise, and his characteristic intuition and boldness, made him less cautious in promoting a corona of hundred

\section{REFERENCES}

Alfvén, H. (1941). On the solar corona. Arkiv för Matematik Astronomi och Fysik 27A.

Alfvén, H. (1947). Magneto hydrodynamic waves, and the heating of the solar corona. Month. Notices Roy. Astronom. Soc. 107:211. doi: 10.1093/mnras/107.2.211

Alfven, H. (1950). Cosmical Electrodynamics. London: Oxford University Press.

Biermann, L. (1951). Kometenschweife und solare Korpuskularstrahlung. Zeitschrift für Astrophysik 29:274.

Chapman, S. (1957). Notes on the solar corona and the terrestrial ionosphere. Smithsonian Contribut. Astrophys. 2:1. doi: 10.5479/si.00810231.2-1.1

Edlén, B. (1937a). Si-ähnliche spektren der elemente titan bis eisen, tivii, vviii, crix, mnx und fexi. Zeitschrift für Physik 104, 188-193. doi: 10.1007/BF01343622

Edlén, B. (1937b). Zur kenntnis der cl i-ähnlichen spektren cli, aii, kiii, caiv, tivi, vvii, crviii, mnix, fex und coxi. Zeitschrift für Physik 104, 407-416. doi: $10.1007 /$ BF01350138

Edlén, B. (1941). An attempt to identify the emission lines in the spectrum of the solar corona. Arkiv för Matematik Astronomi och Fysik 28B.

Edlén, B. (1943). Die Deutung der Emissionslinien im Spektrum der Sonnenkorona. Mit 6 Abbildungen. Zeitschrift für Astrophysik 22:30.
$\mathrm{eV}$ particles in thermal equilibrium. Alfvén also advanced the discussion by obtaining a profile for temperature, modeling the profile mathematically, giving equations to relate temperature and maximum ionization potential, and explaining that radiative losses and hence the heating requirement are small.

Alfvén (1941) was prescient of later paradigm changes too. Alfvén's argument that there must be interplanetary density because heat is conducted to it significantly preceded comet tail and zodiacal light estimates of interplanetary plasma density (Biermann, 1951; Siedentopf et al., 1953), and it was prescient compared to the recognition by Chapman (1957) that conduction extends the corona past 1 AU, which Parker (1958) attributed as leading him to the solar wind. On which, notice Alfvén's statement that if the temperature falls more slowly than inverse radial distance then "the gas is expelled from the Sun.”

Alfvén (1941) does not, in my view, have precedence over Edlén (1941) and Grotrian (1939), but it is a remarkable paper that took the argument further, and one wonders how differently science would have advanced had it received more attention.

I propose: The Sun's million-degree hot corona, established by Edlén (1941, 1943), using the insight of Grotrian (1939), with important physical implications pointed out by Alfvén (1941).

\section{AUTHOR CONTRIBUTIONS}

The author confirms being the sole contributor of this work and approved it for publication.

\section{ACKNOWLEDGMENTS}

I thank Prof. Eric Priest for reviewing the article with constructive enthusiasm and for making excellent suggestions that significantly improved the paper. I also thank Prof. Gunnar Hornig for his assistance reading primary sources in German. NASA's Astrophysics Data System and the University of Dundee's librarians were invaluable for researching this article.

Edlén, B. (1945). The identification of the coronal lines (George Darwin Lecture). Month. Notices Roy. Astron. Soc. 105:323. doi: 10.1093/mnras/105.6.323

Grotrian, W. (1931). Ergebnisse der Potsdamer Expedition zur Beobachtung der Sonnenfinsternis am 9. Mai 1929 in Takengon (Nordsumatra). 6. Mitteilung. Über die Intensitätsverteilung des kontinuierlichen Spektrums der inneren Korona. Mit 8 Abbildungen. (Eingegangen am 27. Juni 1931). Zeitschrift für Astrophysik 3:199.

Grotrian, W. (1934). Über das Fraunhofersche Spektrum der Sonnenkorona. Mit 10 Abbildungen. Zeitschrift für Astrophysik 8:124.

Grotrian, W. (1939). Zur Frage der Deutung der Linien im Spektrum der Sonnenkorona. Naturwissenschaften 27:214. doi: 10.1007/BF01488890

Hufbauer, K. (1991). Exploring the Sun : Solar Science Since Galileo. Baltimore, MD; London: The Johns Hopkins University Press.

Hunter, A. (1942). Origin of the coronium lines. Nature 150, 756-759. doi: $10.1038 / 150756 \mathrm{a} 0$

Lyot, B. (1937). Quelques Observations de la Couronne Solaire et des Protuberances en 1935. L'Astronomie 51, 203-218.

Milne, E. A. (1945). (Presidential Address) , on presenting the Gold Medal to Professor Bengt Edlén. Month. Notices Roy. Astron. Soc. 105:138.

Parker, E. N. (1958). Dynamics of the interplanetary gas and magnetic fields. Astrophys. J. 128:664. doi: 10.1086/146579 
Persson, W., and Martinson, I. (1994). Professor Bengt Edlén in memoriam (1906 10 February 1993). Phys. Script. 51, 5-6. doi: 10.1088/0031-8949/1994/T51/E02

Peter, H., and Dwivedi, B. N. (2014). Discovery of the Sun's milliondegree hot corona. Front. Astron. Space Sci. 1:2. doi: 10.3389/fspas.2014. 00002

Siedentopf, H., Behr, A., and Elsässer, H. (1953). Photoelectric observations of the zodiacal light. Nature 171, 1066-1067. doi: 10.1038/1711066a0

Swings, P. (1943). Edlén's Identification of the Coronal Lines with Forbidden Lines of Fe X, XI, XIII, XIV, XV; Ni XII, XIII, XV, XVI; Ca XII, XIII, XV; a X, XIV. Astrophys. J. 98, 116-128. doi: 10.1086/144550
Conflict of Interest Statement: The author declares that the research was conducted in the absence of any commercial or financial relationships that could be construed as a potential conflict of interest.

Copyright (C) 2018 Russell. This is an open-access article distributed under the terms of the Creative Commons Attribution License (CC BY). The use, distribution or reproduction in other forums is permitted, provided the original author(s) and the copyright owner are credited and that the original publication in this journal is cited, in accordance with accepted academic practice. No use, distribution or reproduction is permitted which does not comply with these terms. 